\title{
Exploring Sexual Diversity: A Case Report on the Application of Habanero Pepper Juice during Recreational Urethral Sounding
}

\author{
Jeremy N. Thomas and D J Williams \\ Idaho State University and Center for Positive Sexuality (Los Angeles)
}

As most of the information on recreational urethral sounding comes from case reports of men seeking medical treatment, there is limited knowledge regarding the variety of ways that sounding is actually conducted as part of sexual gratification. This article reports on the novel case of a middle-aged man applying habanero pepper juice during the sounding process. Implications for theoretical framing as well as guidance for health care providers and other clinicians are discussed.

Recreational urethral sounding (hereafter sounding) is an unconventional but not necessarily rare sexual practice (Breyer \& Shindel, 2012). Typically performed by men in conjunction with masturbation and other sexual activities (Rinard et al., 2010), sounding involves the insertion of objects into the urethra, including not only metal or plastic dilators specifically designed for the purpose, but also any of an array of commonly available household items such as pens and pencils, spoon and fork handles, hairpins, and Q-tips (Hogan, Young, Gabbert, \& Armstrong, 2011; Rinard et al., 2010). Related activities include recreational catheterization (Hogan et al., 2011), piercing the urethra for sexual or aesthetic purposes (Thomas, Crosby, \& Milford, 2015), and the insertion of liquids into the urethra such as wax, alcohol, and baby oil (Hogan et al., 2011; Rinard et al., 2010).

Sounding is associated with health risks including urinary tract infections (Breyer \& Shindel, 2012; Hogan et al., 2011), bleeding (Kwong \& Larner, 2012), strictures (Amiroune, Bouchikhi, \& Adawi, 2014; Rahman, Elliott, \& McAninch, 2004), and loss of foreign bodies (Chipde, Pradhan, Yadav, Kapoor, \& Kapoor, 2012; Song et al., 2013). Sounding is also associated with psychiatric disturbance (Boyle, Martinez, Mennie, Rafiei, \& Carrion, 2013; Rahman et al., 2004; Song et al., 2013), substance abuse (Breyer \& Shindel, 2012; Rahman et al., 2004), and high risk sexual behavior (Breyer \& Shindel, 2012).

\section{Theoretical Framing}

Consistent with the above cited literature, most academic considerations of sounding have been framed in terms of a medical model that clearly pathologizes the practice (Rinard et al., 2010; see Thomas et al., 2015). Yet, in recent years, there have been hints of scholarship (e.g., Ando, Rowen, \& Shindel, 2014; Williams \& Storm, 2012) that suggest that sounding may be better understood in terms of sexual diversity and/or as 
a type of leisure activity. Along these lines, an alternative theoretical frame from which to consider sounding is to investigate the practice as a type of BDSM activity (Turley, 2016), particularly from the perspective of understanding BDSM as leisure (Newmahr, 2010; Williams, Prior, Alvarado, Thomas, \& Christensen, 2016).

This article presents a novel case that illustrates this framing. Although not generalizable, this case provides the opportunity to explore one of the many ways that sounding is actually conducted, as well as the opportunity to consider how a BDSM as leisure perspective can join with a medical model to provide a more holistic understanding of sounding and the associated contexts in which it is practiced.

\section{Case Report}

In this case report, the authors, both behavioral scientists, report on a novel type of sounding practice that they observed during a public event at a BDSM club located in a major metropolitan area of the western United States. At this particular event, a middleaged man demonstrated his practice of applying habanero pepper juice during the sounding process.

The authors encountered this case while observing more common BDSM activities (such as flogging and bondage) at a public event. During this event, a middleaged man along with a younger woman performed a medical role playing scene (see Steele, 2001), respectively acting as patient and nurse. As part of this role play, the man wore a standard patient gown while the woman wore an embellished nurse's costume. The scene began with the woman pretending to conduct an anatomical inspection of the man before then taking his oral temperature with what appeared to be a standard thermometer.

Following this, the woman instructed the man to remove his gown and to lie down on an examination table. As he did, the woman put on a pair of latex gloves, and at about this same time, the man's penis became noticeably erect. The woman then brought out what appeared to be a water-based lubricant as well as a small case of Hegar urethral sounds. The man watched as the woman lubricated and prepared to insert one of the sounds. Taking her time, the woman slowly inserted the sound into the man's erect penis to a depth of approximately 3 to 4 inches. At this point, the man appeared to be enjoying himself, and he verbally thanked the woman for inserting the sound.

After a few minutes, the role play continued with the woman removing the sound and instructing the man that he needed "a new medication" that must be "carefully administered" into his urethra. She then brought out a clear plastic bag that contained what we were told was a medium sized, red-orange habanero pepper. Research indicates that this type of pepper is typically estimated to have a heat factor of approximately 250,000 Scoville Heat Units based on Scoville Organoleptic Testing (Bosland \& Walker, 2010). The woman carefully pulled apart this pepper and exposed its seeds and juice. She 
then removed her gloves and put on a new pair in an apparent effort to prevent crosscontamination.

Following this, the woman took the sound that she had previously used and carefully rubbed the tip of the sound into the exposed seeds and juice. The woman then checked to confirm that there was only juice and not seeds or other debris at the tip of the sound. At this point, the woman added more lubricant to the sound and then slowly reinserted it in to the man's still erect penis. While the man was tense at first, he quickly relaxed as the sound was again inserted to a depth of approximately 3 to 4 inches.

Based on the man's reaction, several seconds then elapsed before the effect of the habanero pepper juice was fully felt. While he initially remained calm, his breathing rate soon increased, and at about this same time, the man began to talk rapidly, making comments that suggested he was very much enjoying the activity. The woman seemed quite pleased with this, and after several minutes of waiting, she removed the sound. For some time thereafter, the man continued to breathe rapidly and his body occasionally convulsed. Throughout this time, the woman spoke to him in a quiet and comforting manner.

In total, the intensity of the man's experience seemed to last for approximately 45 minutes. When the sensation had finally subsided, the man's physiological functioning appeared to return to normal, and the encounter ended. The man thanked the woman and stated that he enjoyed the experience. Other individuals who had also been watching the scene noted that although this form of BDSM activity is uncommon, this particular couple enjoys this form of role play from time to time.

At a later point following this event, the authors note that they were able to track down the man and woman whose activities are described above, and the authors were able to secure their consent for the purposes of this case report.

\section{Discussion}

When considered from the perspective of a medical model, sounding is frequently presented as absurd (Boyle et al., 2013), pathological (Rahman et al., 2004), and psychotic (Song et al., 2013). Yet as considered from a BDSM as leisure perspective, this case illustrates how sounding can be an enjoyable expression of sexual diversity that is personally meaningful and, at least in this particular case, a practice that can be supported and affirmed by a community context. Furthermore, as is consistent with the academic literature on BDSM (Turley \& Butt, 2015), this case demonstrates that the physiological intensity sought and observed in this scenario need not be understood as evidence of psychiatric disturbance, but rather may be better understood as a novel expression of what is a relatively common interest in sensation seeking (Bancroft et al., 2004; Zuckerman, 2007). 
Alongside these implications for theoretical framing, this case suggests potential guidance for health care providers and other clinicians. Perhaps most importantly, the particularities of this case should alert health care providers to the fact that sounding is practiced in a variety of ways and that such variety may be clinically relevant, especially for men seeking medical treatment. Accordingly, health care providers should strive to obtain thorough and detailed information regarding how specific variations in sounding practices may potentially be connected to specific presenting concerns (Hogan et al., 2011; Rahman et al., 2004; Rinard et al., 2010). For example, as shown in this case, it may be valuable to not only inquire about the size and type of object(s) used as part of the sounding process, but also as to any liquids or other substances that may have been used to increase physiological intensity or to enhance erotic stimulation. Although there is only limited academic speculation regarding how liquids or other substances may affect the medical risks associated with sounding - and no published information whatsoever regarding the application of habanero pepper juice-it certainly seems reasonable to warn health care providers that some varieties of sounding practices may potentially incur greater medical risks.

For other clinicians, such as psychologists and therapists, this case also suggests the importance of avoiding assumptions or stereotypes about what sounding is and how and why it is conducted. Instead, clinicians should ask their clients to provide detailed descriptions of their sounding practices and then trust their clients to establish the personal meaning and significance of these practices. Rather than relying on a medical model that pathologizes sounding, clinicians should be open to understanding sounding as an expression of sexual diversity and/or leisure activity.

Finally, the novelty of this case demonstrates the importance of ongoing research in order to not only broaden clinical knowledge of the various ways that sounding is actually conducted but also to expand more generally a sexological understanding of this understudied practice.

Amiroune, D., Bouchikhi, A. A., \& Adawi, F. (2014). Retained self-inserted foreign body into the urethra associated with sequela urethral stenosis: A case report. Journal of Medical Case Reports, 8, 244. doi: 10.1186/1752-1947-8-244

Ando, K. A., Rowen, T. S., \& Shindel, A. W. (2014). Alternative Sexualities: Implications for the urologist. Current Urology Reports, 15(5), 1-9. doi: 10.1007/s11934-014-0405-6

\section{References}

\author{
Bancroft, J., Janssen, E., Carnes, L., Goodrich, \\ D., Strong, D., \& Long, J. S. (2004). \\ Sexual Activity and Risk Taking in \\ Young Heterosexual Men: The \\ Relevance of Sexual Arousability, \\ Mood, and Sensation Seeking. The \\ Journal of Sex Research, 41(2), 181- \\ 192. doi: 10.1080/00224490409552226 \\ Bosland, P. W., \& Walker, S. J. (2010). \\ Measuring chili pepper heat, Guide H- \\ 237. Retrieved from Chili Pepper \\ Institute, New Mexico State University
}


website:

http://aces.nmsu.edu/pubs/_h/H237.pdf

Boyle, A., Martinez, D. R., Mennie, P. A., Rafiei, A., \& Carrion, R. (2013). The time-less urologic question,"Now why would you do that?" A case series and literature review of self-inserted urethral foreign bodies. Journal of Clinical Urology, 7(3), 165-169. doi: 10.1177/2051415813496562

Breyer, B. N., \& Shindel, A. W. (2012). Recreational urethral sounding is associated with high risk sexual behaviour and sexually transmitted infections. British Journal of Urology, 110(5), 720-725. doi: 10.1111/j.1464410X.2011.10810.x

Chipde, S. S., Pradhan, M. R., Yadav, A., Kapoor, R., \& Kapoor, R. (2012). Foreign body remained in urethra for 12 years: A rare presentation of a common problem with a short review of the literature. Turkish Journal of Urology, 38(4), 239-243. doi: 10.5152/tud.2012.051

Hogan, L., Young, C., Gabbert, W., \& Armstrong, M. L. (2011). Unique predisposing factors for male urinary tract infections. Journal of the American Academy of Nurse Practitioners, 23(10), 525-529. doi: 10.1111/j.1745-7599.2011.00649.x

Kwong, T., \& Larner, T. (2012). A rare and unusual case of urethral bleeding. British Medical Journal Case Reports, 2012. doi: 10.1136/bcr-2012-6155

Newmahr, S. (2010). Rethinking kink: Sadomasochism as serious leisure. Qualitative Sociology, 33(3), 313-331. doi: 10.1007/s11133-010-9158-9

Rahman, N. U., Elliott, S. P., \& McAninch, J. W. (2004). Self-inflicted male urethral foreign body insertion: Endoscopic management and complications. British Journal of Urology International, 94(7), 1051-1053. doi: 10.1111/j.1464410X.2004.05103.X
Rinard, K., Nelius, T., Hogan, L., Young, C., Roberts, A. E., \& Armstrong, M. L. (2010). Cross-sectional study examining four types of male penile and urethral 'play'. Urology, 76(6), 13261333. doi: 10.1016/j.urology.2010.03.080

Song, J. B., Tanagho, Y. S., Haseebuddin, M., Benway, B. M., Desai, A. C., Bhayani, S. B., \& Figenshau, R. S. (2013). Endoscopic management of genitourinary foreign bodies. Reviews in Urology, 15(2), 84-91.

Steele, V. (2001). Fashion, fetish, fantasy. In E. Tseelon (Ed.), Masquerade and Identities: Essays on Gender, Sexuality and Marginality (pp. 73-82). New York: Routledge.

Thomas, J. N., Crosby, L., \& Milford, J. (2015). Gender differences among self-reported genital piercing stories. Deviant Behavior, 36(6), 441-462. doi: 10.1080/01639625.2014.944062

Turley, E. L. (2016). 'Like nothing I've ever felt before': Understanding consensual BDSM as embodied experience. Psychology \& Sexuality, 7(2), 149-162. doi: 10.1080/19419899.2015.1135181

Turley, E. L., \& Butt, T. (2015). BDSM Bondage and discipline; dominance and submission; sadism and masochism. In C. Richards \& M. J. Barker (Eds.), The Palgrave Handbook of the Psychology of Sexuality and Gender (pp. 24-41). New York: Palgrave Macmillan.

Williams, D. J., Prior, E. E., Alvarado, T., Thomas, J. N., \& Christensen, M. C. (2016). Is Bondage and Discipline, Dominance and Submission, and Sadomasochism Recreational Leisure? A Descriptive Exploratory Investigation. The Journal of Sexual Medicine. 13, 1091-1094. doi: 10.1016/j.jsxm.2016.05.001

Williams, D. J., \& Storm, L. E. (2012). Unconventional leisure and career: Insights into the work of professional dominatrices. Electronic Journal of Human Sexuality, 15.

Zuckerman, M. (2007). Sensation Seeking and Risk. Washington, D.C.: American Psychological Association 